\title{
Forecasting tropical ENSO-induced drought conditions using sea surface height in the Western Pacific
}

\section{Carlos Primo David}

University of the Philippines Diliman

Manuel Justin Custado

University of the Philippines Diliman

Natasha Sekhon

Brown University

Daniel Ibarra ( $\nabla$ daniel_ibarra@brown.edu )

Brown University

\section{Research Article}

Keywords: El Niño Southern Oscillation, Sea surface temperature, sea surface height

Posted Date: October 15th, 2021

DOl: https://doi.org/10.21203/rs.3.rs-926783/v2

License: (a) (i) This work is licensed under a Creative Commons Attribution 4.0 International License.

Read Full License 
1 Forecasting tropical ENSO-induced drought conditions using sea

$6{ }^{1}$ National Institute of Geological Sciences, University of the Philippines Diliman, Quezon City,

$7 \quad$ Philippines

$8 \quad{ }^{2}$ Department of Earth, Environmental, and Planetary Sciences, Brown University, Providence

9 RI, USA

$10{ }^{3}$ Institute at Brown for Environment and Society, Brown University, Providence RI, USA

11

$12 *$ Corresponding author: daniel_ibarra@brown.edu 


\section{Abstract}

14 The interannual variability of rainfall caused by the El Niño Southern Oscillation (ENSO) results

15 in significant changes in hydrologic conditions that affect entire countries' water supply.

16 Forecasting ENSO and its impacts are mainly based on Central Pacific Sea surface temperature

17 (SST) anomalies which satisfactorily correlates with timing and, to a lesser extent, the intensity of

18 drought conditions in the Philippines and the rest of the Western Pacific during the El Niño phase.

19 Changes in sea surface height (SSH) are also brought upon by ENSO through density changes with

20 temperature and oceanographic processes. Here, we report that the associative nature of SSH and

21 drought as measured by surface runoff, has a stronger correlation $(r>0.693, p<0.05)$ in terms of

22 the expected timing, with 1 to 3 months lag time, and intensity compared to using traditional ENSO

23 SST indices from the Central Pacific. Furthermore, since SSH is co-located with its corresponding

24 forecasted decrease in runoff, a localized prediction can be made which further increases the

25 accuracy of this predictive tool. In the wake of a changing climate, this work demonstrates the

26 possibility of statistically forecasting the timing of precipitation, and thus the volume of surface

27 water availability, using local SSH as an indicator. A tool which is necessary for time-sensitive

28 management decision making in drought-prone tropical regions.

30 Main

31 The El Niño Southern Oscillation (ENSO) results in significant deviations in continental

32 precipitation primarily in the Eastern Pacific but its effects on the water cycle are felt via 33 atmosphere-ocean teleconnections across the globe ${ }^{1}$. ENSO is triggered by sea surface temperature

34 (SST) anomalies emanating from the Central and Eastern Pacific and is primarily used to predict

35 the ensuing ENSO impacts. Significant work has been done in fine tuning SST-based indicators 
36 such as constraining the region of warming, resulting in the identification of the Nino Index

37 Regions $^{2}$ and the development of the Oceanic Nino Index $(\mathrm{ONI})^{3}$. Further, the recognition of

38 different ENSO "flavors" has led to the development of other indices ${ }^{4}$, the use of dynamic

39 ocean/atmosphere coupled models ${ }^{5,6}$ and improved data calculation and interpolation techniques ${ }^{7,8}$

40 in order to extend and potentially improve the accuracy of predictions for impacts associated with

41 ENSO teleconnections. A majority of these improvements are geared towards predicting impacts

42 in the Eastern Pacific; however, research is increasingly focusing on forecasting ENSO impacts in

43 other regions owing to this phenomenon's far-reaching effects on global climate variability on

44 interannual timescales, occurring every two to seven years ${ }^{9}$.

46 Many counter-intervening processes are in operation in the Central and Eastern Pacific, including

47 the timing of the annual cycles of outgoing longwave radiation which affects atmospheric

48 convection and in turn controls the location and intensity of warming in the tropical Pacific ${ }^{3}$.

49 Further, ocean-atmosphere coupled models have also been found to be less accurate in predicting

50 the global SST pattern during weak ENSO events ${ }^{10}$. Similar ocean-atmosphere interactions in the

51 Western Pacific and other parts of the globe may likewise complicate the ensuing ENSO impact

52 in the countries bordering the Western Pacific. Thus, a more localized indicator of interannual

53 variability is required to provide better predictive capabilities for these countries beyond the

54 indices based solely on the Central and Eastern Pacific SST anomalies. In this work we explore

55 such an indicator using sea surface height as a predictive tool for tropical drought as measured by

56 the ensuing decrease in river runoff. 
$58 \mathrm{SSH}$ is directly tied to temperature as warm water is less dense than cold water, such that locally

59 higher SSH regions tend to be warmer than lower SSH areas ${ }^{11,12}$ coupled with strong eastward

60 Kelvin waves that trap coastal waters in the Eastern Pacific coast ${ }^{13}$. SSH's relationship with 61 temperature led Shi et al. ${ }^{14}$ to recently differentiate Central Pacific from Eastern Pacific El Niño

62 types through the development of an SSH-based Index rather than the more traditionally used SST-

63 based indices. Finally, researchers have also previously recognized the strong association between

64 low rainfall conditions and low sea surface height (SSH) in Indonesia ${ }^{15}$.

66 Situated in the equatorial Western Pacific, the Philippine Archipelago is ten thousand kilometers

67 away from the Central Pacific yet extremely affected by ENSO variability, albeit with the reverse

68 sign of what is experienced in the Eastern Pacific. During the El Niño phase, drought conditions

69 are felt across the different islands of the country ${ }^{15}$. SST anomalies generally correlate with

70 drought conditions in the Western Pacific but become less accurate with regards to the onset and

71 expected intensity of drought vis a vis the intensity of ENSO conditions. In fact, the onset of the

72 2009-2010 moderate intensity El Niño years resulted in extensive rainfall in the Philippines ${ }^{16}$, the

73 opposite of the canonically expected sign. This is due to other compounding factors such as the

74 varying rainfall and temperature signatures of each ENSO event and their susceptibility to the

75 hydroclimate character of the preceding years ${ }^{15}$. The decrease in rainfall due to El Niño conditions

76 also varies in magnitude across the country with unpublished data on highest precipitation

77 anomalies being reported to affect the country's eastern seaboard while combined precipitation

78 and temperature anomalies are highest in the middle of the largest Philipipne islands, Luzon and

79 Mindanao. Given the motivating need for a more localized indicator of drought, this paper presents

80 the use of local SSH measurements as a high-resolution indicator of drought conditions across the 
81 Philippine Archipelago in an analogous sense to using ENSO indices for such forecasting. To the

82 best of our knowledge, this is the first time that it is being reported that SSH data is used for

83 localized ESNO-related drought prediction.

84

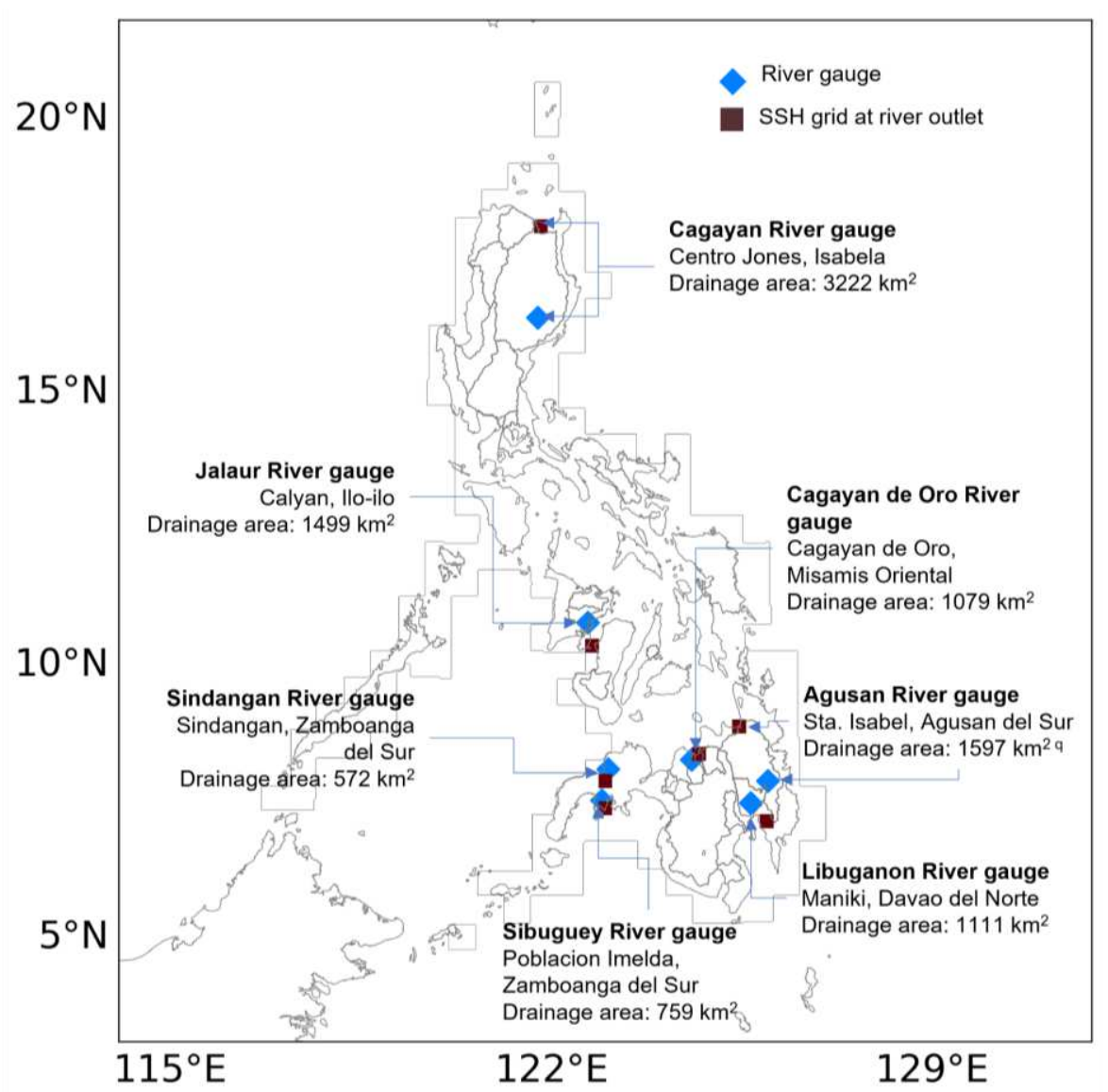

86 Figure 1. Location of the seven river basins analyzed in this study including where the actual river

87 gauge station is located as well as each river's outlet to the ocean. The thin, gray lines bordering

88 the coastal waters of the country correspond to the spatial overlap of the SSH and GRUN datasets.

\section{River gauge, GRUN and SSH data}

91 A comparison between actual stream gauge data of major rivers in the Philippines with at least ten

92 years of GRUN data is provided in Extended Data Table 1. As reported by Ibarra et al. ${ }^{17}$, actual 
93 stream gauge and the global gridded runoff dataset generally show a fair correlation between them

94 which can further be improved upon correction of systematic biases. The same table directly

95 correlates stream gauge data with SSH where the r-value is given for the lag time that showed the

96 highest correlation. Data for SSH also shows high correlation with actual stream gauge data for

97 almost all of the large basins considered. This points to the validity of the two parameters' strong

98 association, and which we then carry over to investigating GRUN-SSH correlations in the below

99 analyses.

100

101 National analysis between GRUN and SSH time series

102 Using the GRUN data, we now correlate river runoff and sea surface height as a national aggregate,

103 regionally and at the basin level. The national annual averages of GRUN and SSH are plotted in

104 Figure 2 where it clearly shows the seasonal cycle of stream runoff including a short dry spell that

105 is usually centered around August every year. A similar but more erratic seasonal cycle is also

106 observed in SSH. Deseasonalizing and detrending the data as shown in the lower figure clearly

107 presents the years with lowest runoff values corresponding well to El Niño years including the two

108 most recent strong El Niño years of 1997-1998 and 2014-2016. The same figure presents the strong

109 association of runoff and SSH with a noticeable time lag during some years. The detrended plot

110 not only shows the similar pattern between the two datasets but also the high association of

111 detrended SSH and runoff values. Again, also evident in Figure 2 are the lowest SSH and runoff

112 values centered on the two strong El Niño events of 1997-98 and 2015-2016. These two events are

113 more than $1.5 \mathrm{~mm} /$ day lower than mean runoff and about $0.1 \mathrm{~m}$ lower than mean SSH.

114 

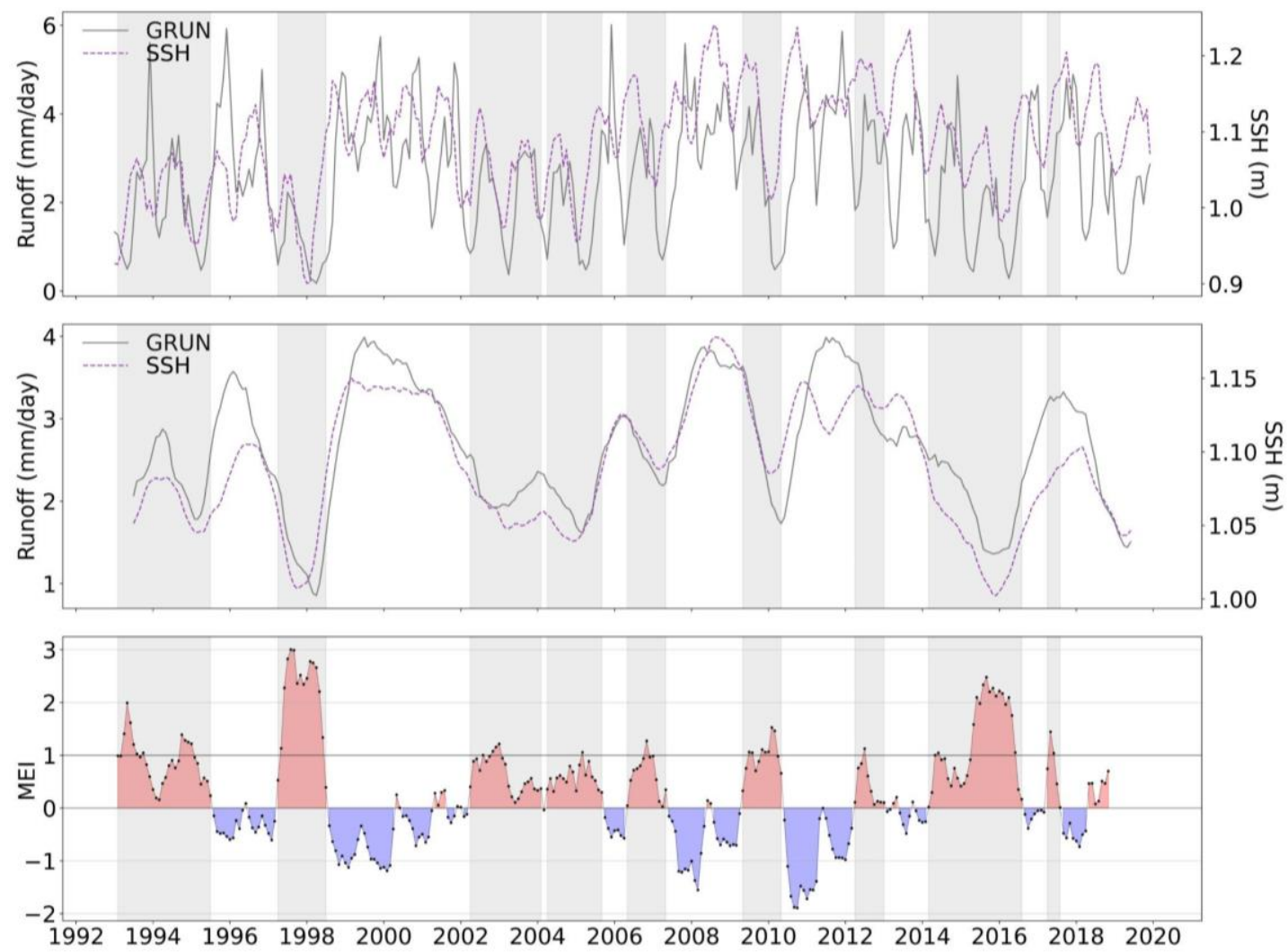

116 Figure 2. Monthly time series of GRUN and SSH, national means during periods of overlap (1993

117 - 2019) and the Multivariate ENSO Index (1993 - 2018). Top: monthly time series of GRUN and

118 SSH; middle: deseasonalized and detrended time series of GRUN and SSH; bottom: the MEI.

119 Highlighted time periods (in gray) correspond to the nine relatively strong El Niño events (peak 120 MEI > 1) used in the regression analysis. From left to right, these time periods are: (1) $12 / 1989$ to

$12107 / 1995$, (2) 04/1997 to 07/1998, (3) 04/2002 to 02/2004, (4) 04/2004 to 09/2005, (5) 05/2006 to 05/2007, (6) $05 / 2009$ to $05 / 2010$, (7) $04 / 2012$ to $01 / 2013$, (8) $03 / 2014$ to $08 / 2016$, and (9) $04 / 2017$

123 to $08 / 2017$.

125 Wavelet analyses of the national averages with and without removing the seasonal cycle and 126 detrending shows a one-year periodicity and correlation between SSH and runoff (Figure 3). 127 Further, as shown by the arrows in the wavelet analyses, across the time series SSH consistently 
128 leads runoff nationally. This is supported by the correlation coefficients derived from the two 129 datasets (Extended Data Table 2), as r-values are highest when SSH leads runoff by 1 to 2 months $130 \quad(\mathrm{r}=0.833-0.835, \mathrm{p}<0.05)$. However, significant correlation between the two parameters still 131 exists even at an SSH lag of 3 months $(r=0.693, p<0.05)$. Extended Data Table 2 also shows that 132 SSH generally correlates with runoff better than SST derived from the Moderate Resolution 133 Imaging Spectroradiometer (MODIS) - Aqua sensor, particularly during positive time lags. Map134 view representations of the correlations at several time lags of SSH relative to runoff generally 135 show relatively high $r$-values across the country (Figure 4). This further suggests the utility of SSH 136 data as a predictor for average runoff levels at the national scale.
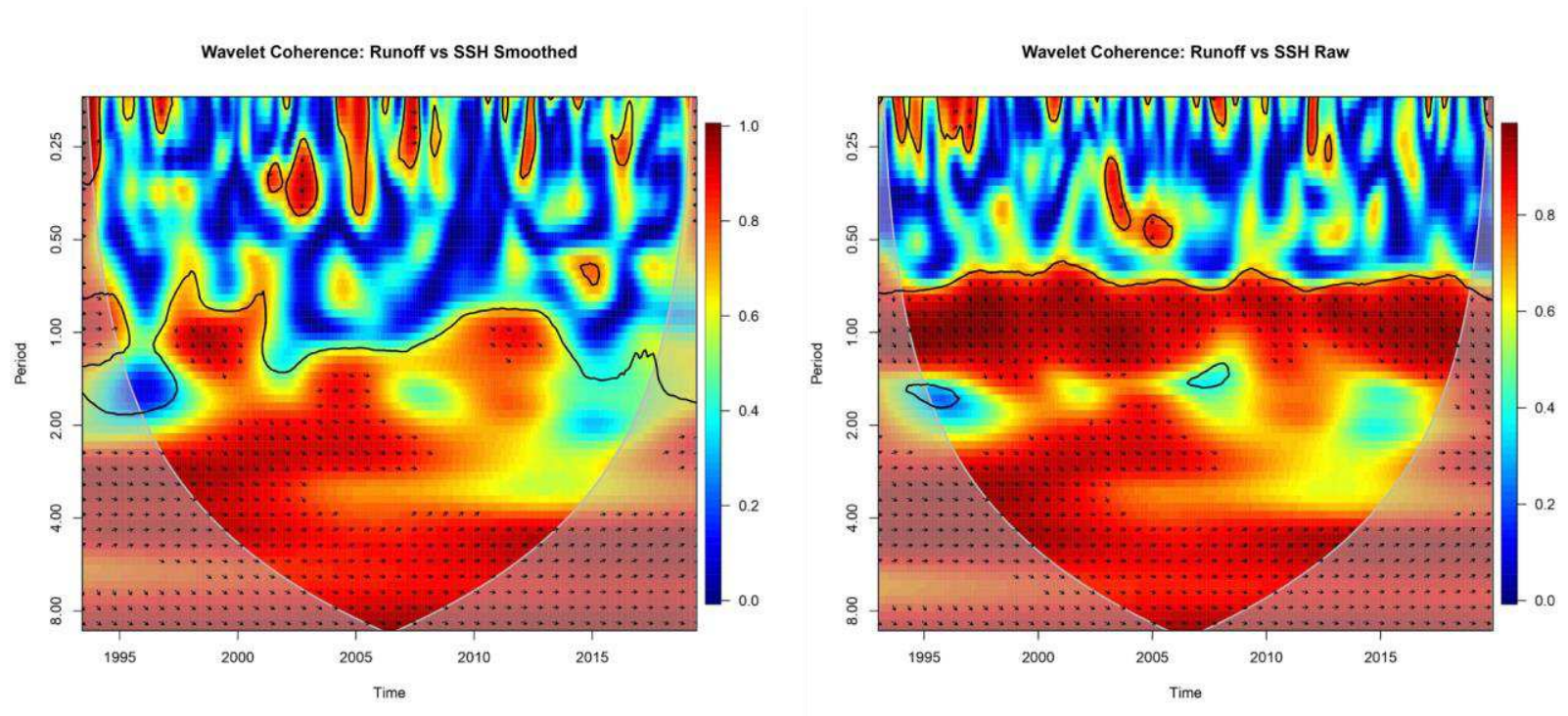

Figure 3. Wavelet coherence plots between runoff and SSH. Direction of arrows indicate time

140 lag; downward direction corresponds to zero time lag, while arrows pointing to the right indicate

141 that SSH leads runoff. Left: Smoothed time series; right: raw time series. 

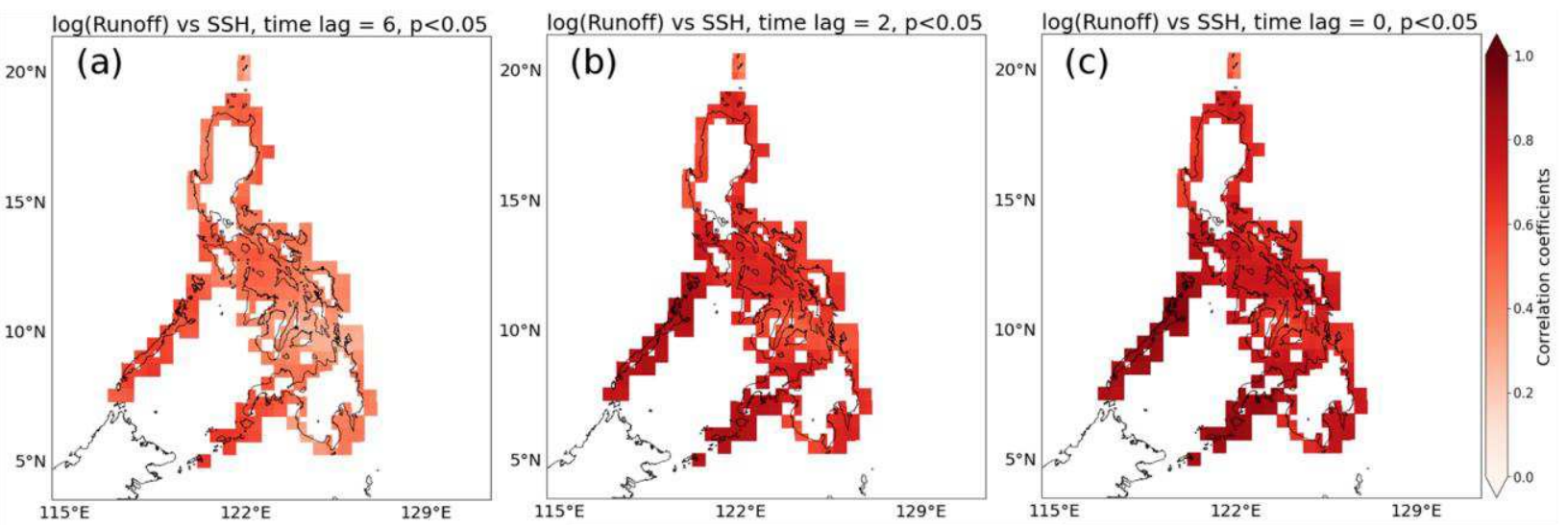

148 Figure 4. Map of correlation coefficients (1993 - 2019). Left to right: (a) at 6 months that SSH

149 precedes runoff, (b) at 2 months that SSH precedes runoff, (c) at no time lag. Time lag in 150 months.

\section{Region-based analysis of SSH and GRUN}

153 To expand the associative nature of SSH and runoff we further our analysis by grouping coastal

154 areas around the Philippines that show similar SSH versus runoff trends. Nine geographic regions

155 are identified in Figure 5 to have coherent characteristics. An illustration of the calculated

156 correlation coefficients for each region is presented in Figure 6. Interestingly, higher SSH and

157 runoff correlations are found on the western side of the country, particularly in Palawan, and the

158 Zamboanga and Sulu region. The lowest SSH versus runoff correlations are observed in areas

159 directly in contact with the Western Pacific such as northern Luzon (Batanes and Cagayan) and

160 the eastern coast of the country (Eastern Luzon and Eastern Mindanao and Samar). 

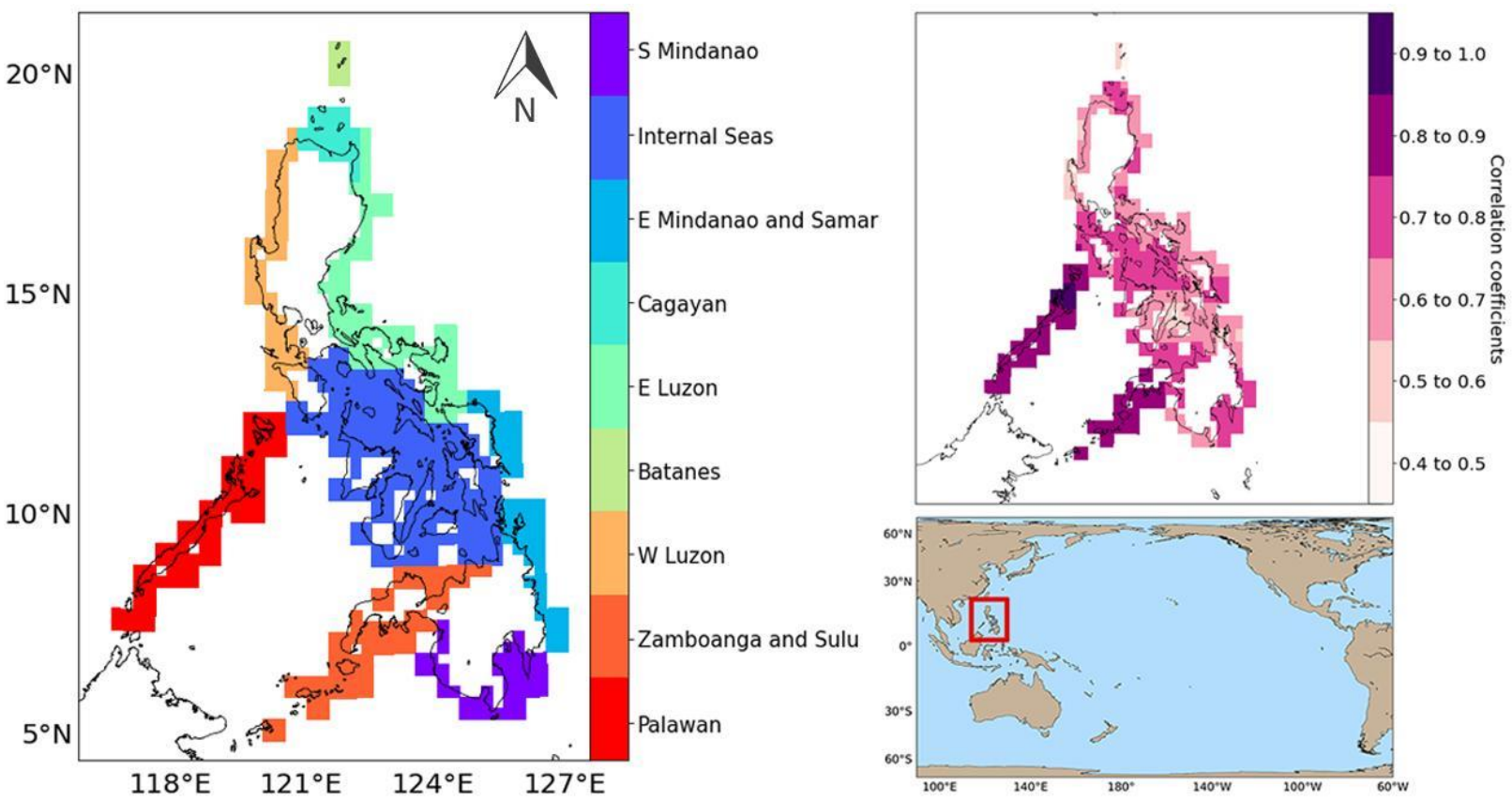

163 Figure 5. Study area divided per region according to the magnitude of correlation coefficients at

$164-1$ month time lag. Right: identified regions; left: reference correlation map at 1 month time lag of SSH and the Pacific Ocean map. Red box indicates the location of the study area.

167 Other than the different correlation values between SSH and runoff, the time lag with the maximum r-value at each identified region also differs from one another (Figure 6). The regions of Palawan,

169 Zamboanga and Sulu, and Southern Mindanao achieve the highest correlation with r-values of $1700.914,0.900$, and 0.813 , respectively at time lags from -1 to -3 months. For Southern Mindanao,

171 the highest correlation is achieved at time lag $=-3$, whereas for the two other regions the time lag 172 with highest correlation is at $\mathrm{t}=-1$. Significant correlations $(\mathrm{r}=0.734$ to 0.775$)$ are also observed

173 for the rest of the regions at time lags of either $t=-1$ or -2 , except for the northernmost islands of 174 the Batanes region, which attains its highest correlation with no time lag. Presumably, the Batanes 175 region is the least affected by SSH variations as it is already 20 degrees north of the equator. 
176 Runoff estimates from may likewise be off due to the small catchment size of the small, individual 177 islands of the region ${ }^{17}$.

178

179

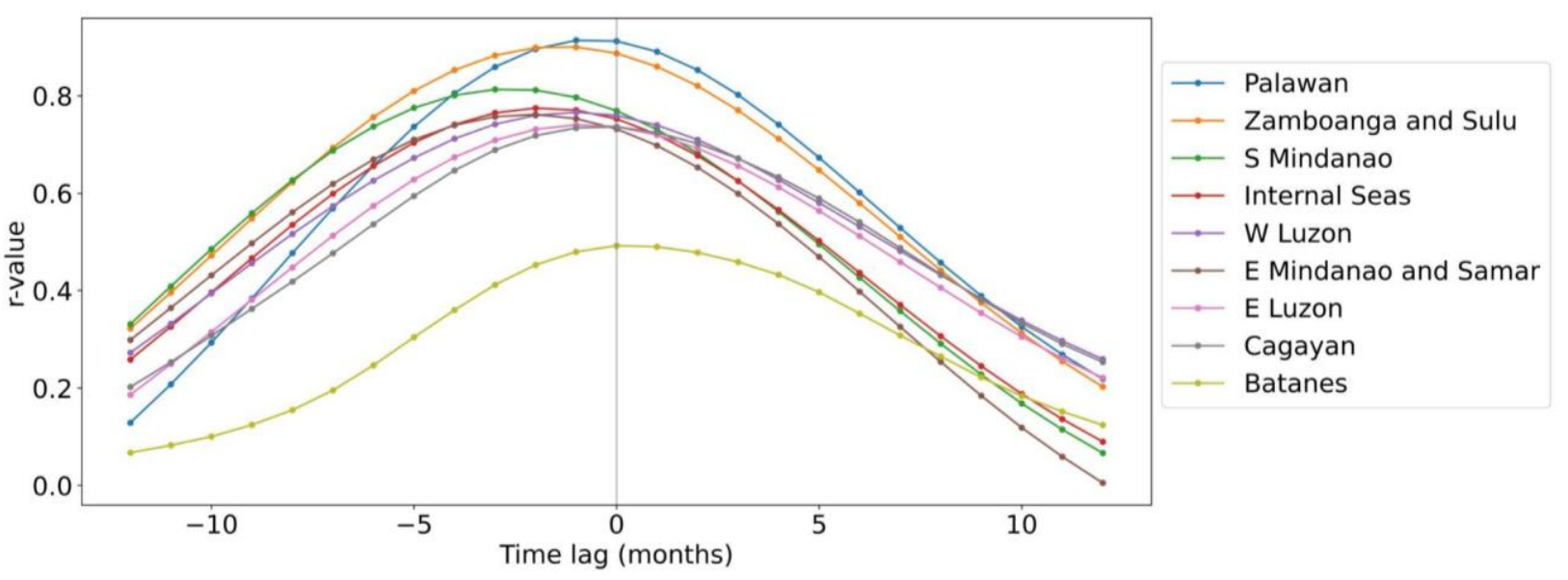

Figure 6. Correlation coefficients between $\log _{10}$ (runoff) and SSH at each region from -12 to 12 months of time lag of SSH. The regions are listed in the plot legend according to the magnitude of correlation coefficients calculated; Palawan and Batanes have the highest and lowest peak r-values, respectively. A positive time lag means SSH precedes runoff; a negative time lag means SSH leads runoff. See Supplementary Table 1 for the matrix of values plotted here.

\section{Drought prediction using SSH during positive phase ENSO events}

In this section, we discuss ENSO-induced drought and its prediction using SSH. For this, we select significant El Niño events $(n=9)$ based on the Multivariate ENSO Index (MEI) within the period of overlap between the GRUN and SSH datasets (1993 to 2018) and isolate the minimum runoff and SSH values that correspond to such events. These El Niño events are identified by the time periods with consistent positive MEI and with a maximum value of MEI > 1: (1) 12/1993 to 07/1995, (2) 04/1997 to $07 / 1998$, (3) $04 / 2002$ to $02 / 2004$, (4) $04 / 2004$ to $09 / 2005$, (5) $05 / 2006$ to 05/2007, (6) $05 / 2009$ to $05 / 2010$, (7) $04 / 2012$ to $01 / 2013$, (8) $03 / 2014$ to $08 / 2016$, and (9) $04 / 2017$ 
194 to 08/2017. Extended Data Table 3 provides the correlation coefficients which again shows the 195 high association between minimum SSH and minimum runoff during drought conditions for most 196 regions. This is especially true for the western side of Luzon $(r=0.937)$ and southern Mindanao

$197(\mathrm{r}=0.901)$ which are the country's largest agricultural lands and regions that are highly susceptible

198 to drought conditions ${ }^{18}$. Extended Data Table 3 shows the time lag wherein SSH can be used as a 199 predictor for minimum runoff during strong El Niño events. Peak correlations range from a 4 200 month time lag to no lag at all depending on the region.

202 Given the results from the preceding sections, we propose the future development of an SSH-based 203 drought forecasting tool for water management purposes. First, the MEI or similar ENSO indices 204 is used to determine the background state of the climate system in the Pacific Ocean with a 205 predictive horizon of 6 to 12 months. If the MEI is greater than 0, drought conditions regionally 206 can be forecasted using the prevailing SSH and the SSH vs. runoff regressions presented above 207 within a 2 to 4-month window of the dry season. A nationwide network of SSH gauging stations 208 must be established for real-time analysis to be possible. Based on the historical correlation of SSH 209 and runoff per region, an appropriate range of probable drought levels based on historical and 210 projected runoff data (calculated as a decrease in rainfall for non-irrigated areas) could then be 211 provided per basin in each and every region.

\section{Conclusions}

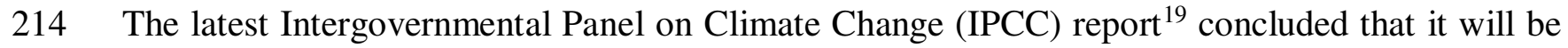

215 virtually certain that the ENSO will remain the dominant mode of interannual variability for 216 precipitation in a warmer world. Moreover, it is very likely that rainfall variability related to 
217 changes in the strength and spatial extent of ENSO teleconnections will lead to significant changes

218 at regional scale ${ }^{19}$. As such, this is a compelling reason why our predictive capabilities of droughts

219 should be further enhanced. Even with only several months in advance, the accurate prediction of

220 local hydrologic conditions coupled with an effective water management program will allow for

221 climate change adaptation measures to be implemented.

223 This study highlights the importance of similar predictive tools that are associative in nature and

224 not necessarily causative. The high correlation of SSH and runoff detailed in this study provides

225 an additional tool for ENSO-induced drought prediction with a shorter predictive horizon (2-4

226 months lead time) but of higher accuracy compared to using the standard central Pacific SST-

227 based tools used to characterize ENSO for global teleconnections. SST anomalies are translated

228 into changes in local SSH values which presumably are affected by other oceanographic factors

229 beyond just SST and subsequentially drive local-scale precipitation and drought conditions. These

230 compounding factors are beyond the scope of this research but may include the seasonal timing of

231 such anomalies, ocean-atmosphere interactions and ocean circulation dynamics. What we presume

232 is that the same factors are also imposed on factors influencing precipitation amount and resulting

233 stream runoff thus leads to the higher correlation between SSH and runoff instead of the causative

234 SST information from the Pacific Ocean basin. This inference is useful for the development of a

235 drought forecasting tool associated with El Niño events with greater accuracy and skill. 


\section{Methods}

\section{Data}

239 The primary data used for this study were monthly composites of SSH and runoff from satellite

240 altimetry records and the GRUN Ensemble dataset, respectively. Drought is herein quantified

241 based on stream discharge, in particular the amount of decrease in the minimum observed flow in

242 rivers. In the following sections, we introduce the origin and data handling of these datasets.

\section{Satellite altimetry data}

245 Daily level-4 SSH products with a spatial resolution of $0.25^{\circ}(\sim 27 \mathrm{~km})$ were retrieved from the

246 Copernicus Marine Environmental Monitoring Service (CMEMS) database. These datasets are the 247 products of the most recent version of the Data Unification and Altimeter Combination System 248 delayed time (DUACS DT2018), implemented since April 2018 to produce merged datasets of all 249 available satellite altimeter missions globally. The altimetry data products were routinely 250 processed and distributed by Aviso from 2003 to 2017 and by the European Copernicus Program 251 since $2015^{20}$. Sea surface height measurements from the datasets refer to the absolute dynamic 252 topography (ADT), which is the SSH above the reference geoid.

254 The DUACS system has continuously been assessed at regional scales by comparing processed 255 sea level anomaly (SLA) data against independent along-track missions and tide gauge data ${ }^{20}$. 256 Overall improvements in the DT2018 products from the DT2014 version were observed using a 257 tide gauges network in the Mediterranean $\mathrm{Sea}^{20}$. Ruiz-Etcheverry et al. ${ }^{21}$ saw good comparisons 258 between tide gauge data and gridded SLA globally, with root-mean-square differences lower than $2592 \mathrm{~cm}$ for $76 \%$ of the sites studied. Larger error values between tide gauges and satellite altimetry 
260 are accounted for by factors such as nearby river discharge (e.g. Ganges River), currents, seasonal

261 sea ice, and large distance between the gauges and regions with dense along-track altimetry data

262 (e.g. Gulf of Thailand and Panama Bay). Sea level errors were quantified at the mesoscale range

263 from $1.4 \mathrm{~cm}^{2}$ to $30 \mathrm{~cm}^{2}$ from low to high variability areas ${ }^{20}$. Independent assessments of altimetry

264 data saw global bias estimates from each satellite mission ${ }^{22,23}$. In previous works, satellite altimetry

265 data have shown great utility in various sea level applications across different study sites, such as

266 the Palau Islands, Malaysia, West Philippine Sea, and Argentina ${ }^{24-27}$.

\section{GRUN Ensemble}

269 The GRUN Ensemble dataset is a global runoff product derived from a machine learning algorithm

270 trained using streamflow observations from the Global Streamflow Indices and Metadata Archive

271 (GSIM). It has a spatial resolution of $0.5^{\circ}(\sim 55 \mathrm{~km})$ spanning from 1901 to 2019 . Only discharge

272 data from catchment basins with areas between 10 and 2,500 $\mathrm{km}^{2}$ were used as training input to

273 the algorithm ${ }^{28,29}$. This version of the GRUN dataset ${ }^{28}$ improves upon the first iteration $^{29}$ by using

274 temperature and precipitation data from an ensemble of 21 global datasets as input to the developed

275 algorithm. Validation of the runoff product utilized discharge data from basins with more than

$27610,000 \mathrm{~km}^{2}$ of area and its accuracy was assessed against nine other global hydrological models ${ }^{28}$.

278 One of the earliest local-scale validations of the GRUN algorithm was conducted by Ibarra et al. ${ }^{17}$

279 by comparing the original version of the runoff product against discharge gauges across the

280 Philippines. They found reasonable utility in the $\log _{10}$-transformed data at the country scale, which

281 further improves when a nationwide bias correction derived from the river gauge comparison is

282 applied. 
River gauge data

285 The Philippines has daily stream gauge data for more than 100 rivers with gauging programs 286 starting as early as the turn of the 20 th Century ${ }^{30}$. Unfortunately, like in many other countries, most 287 gauging data are not continuous and thus we use the global GRUN dataset as a proxy for 288 streamflow. For this study, stream gauging data of seven of the 18 major river basins of the country 289 were selected on the basis of location, period of the gauging data available, and the size of the 290 drainage basin area (Figure 1). These were directly compared to SSH values of the grid overlapping 291 with each of the rivers' outlet to the ocean as a verification of our methods.

\section{Data pre-processing}

294 The GRUN data files were transformed to $0.25^{\circ} \times 0.25^{\circ}$ spatial resolution using the conservative 295 nearest-neighbor interpolation method to match with the retrieved SSH data. Daily SSH data were 296 averaged to obtain monthly composites. All the data were spliced to an area bounded by 3.125 to $29722.125^{\circ} \mathrm{N}$ and 114.125 to $131.875^{\circ} \mathrm{E}$. River gauge data were converted from liters/second to $298 \mathrm{~mm} /$ day to match with the GRUN dataset using the basin areas reported in Ibarra et al. ${ }^{17}$.

300 Data analysis

301 The runoff dataset was $\log _{10}$-transformed following Ibarra et al. ${ }^{17}$ based on their comparison to the 302 original version of GRUN, while the SSH dataset was not normalized or $\log _{10}$-transformed. We do 303 this because runoff values vary by several orders of magnitude and represent heavy tailed 304 distributions while SSH values only vary by a small amount $(\sim 37 \%)$. 
306 In order to minimize the influence of seasonal cycles and long-term linear trends, all datasets were

307 deseasonalized and detrended prior to correlation analysis. The seasonality was removed by taking

308 the 12-month centered moving average of each time series. Afterwards, linear regression was

309 applied to each time series to obtain the corresponding linear trend, represented by the resulting

310 equation of the line. The linear trends were then subtracted from the deseasonalized data to obtain

311 the detrended time-series datasets.

313 Linear correlation analysis was implemented on all the grids within the spatial and temporal 314 overlaps of the data (1993 to $2019, \mathrm{n}=312)$ at -12 to 12 -month time lag/time ahead relative to

315 SSH. Streamflow values were $\log _{10}$-transformed and correlated with the SSH grid at the discharge

316 site of the drainage basins where the gauges are located. Figure 1 shows the location of the river

317 gauge and corresponding gauges in seven of the major river basins of the country. It also shows

318 the actual coverage of the SSH and GRUN grid used in this study.

\section{Data availability}

321 All datasets are available from the papers cited in the above methods and are available in the code 322 package provided with the paper.

\section{Code availability}

325 All python code is provided in a code package (zip file) associated with submission and is available as a Google Colaboratory Notebook linked in the Readme file. 
329 We acknowledge a 2019 DOST-PCIEERD Balik Scientist award to DEI and CPD which initiated

330 the collaboration and Pamela Louise M. Tolentino and Mart Geronia for discussions and help with

331 dataset curation. NS is funded by Voss Postdoctoral Research Associate and Presidential Diversity

332 Postdoctoral Fellowships from Brown University.

334 Author Information

335 Affiliations

336 National Institute of Geological Sciences, University of the Philippines Diliman, Quezon City, 337 Philippines

338 C.P. David and M.J. Custado

339 Department of Earth, Environmental, and Planetary Sciences, Brown University, 340 Providence RI, USA and Institute at Brown for Environment and Society, Brown University,

341 Providence RI, USA

342 D.E. Ibarra and N. Sekhon

344 Contributions

345 CPD, DEI and MJC designed the study. MJC, DEI and NS conducted the analysis. MJC and 346 CPD wrote the initial manuscript draft. MJC and DEI produced the figures. All authors

347 contributed to the interpretation of the results and to editing the manuscript.

\section{Corresponding author}

350 Correspondence to D.E. Ibarra. 
352 Ethics declarations

353 Competing interests

354 The authors declare no competing interests. 


\section{References}

$356{ }^{1}$ Kousky, V.E., Kagano, M.T., and Cavalcanti, I.F.A. A Review of the Southern Oscillation:

357 Oceanic-Atmospheric Circulation Changes and Related Rainfall Anomalies. Tellus A 36A

$358 \quad(5), 490-504(1984)$.

$359{ }^{2}$ Rasmusson, E.M. and Carpenter, T.H. Variations in Tropical Sea Surface Temperature and

360 Surface Wind Fields Associated with the Southern Oscillation/El Niño. Monthly Weather

$361 \quad$ Review $110(5), 354-384$ (1982).

$362{ }^{3}$ Trenberth, K.E. The Definition of El Niño. Bulletin of the American Meteorological Society 78

363 (12), 2771-2777 (1997).

$364{ }^{4}$ Trenberth, K.E. and Stepaniak, D.P. Indices of El Niño Evolution. Journal of Climate 14 (8), 365 1697-1701 (2001).

3665 Tozuka, T. and Yamagata, T. Annual ENSO. Journal of Physical Oceanography 33 (8), 1564$367 \quad 1578(2003)$

$368{ }^{6}$ Wengel, C., Lee, SS., Stuecker, M.F. et al. Future high-resolution El Niño/Southern Oscillation 369 dynamics. Nat. Clim. Chang. 11, 758-765 (2021).

$370{ }^{7}$ Kirtman, B.P. The COLA Anomaly Coupled Model: Ensemble ENSO Prediction. Monthly

$371 \quad$ Weather Review 131 (10), 2324-2341 (2003).

$372{ }^{8}$ Zambrano Mera, Y.E., Rivadeneira Vera, J.F., and Pérez-Martín, M.Á. Linking El Niño

373 Southern Oscillation for Early Drought Detection in Tropical Climates: The Ecuadorian 374 Coast. Science of The Total Environment 643, 193-207 (2018).

3759 Sarachik, E.S. and Cane, M.A. The El Niño-Southern Oscillation Phenomenon. (Cambridge $376 \quad$ University Press, 2010).

$377{ }^{10}$ Sohn, S.J., Tam, C.Y., and Jeong, H.I. How Do the Strength and Type of ENSO Affect SST 
Predictability in Coupled Models. Scientific Reports 6, 1-8 (2016).

379

380

381

382

383

384

385

386

387

388

389

390

391

392

393

394

395

396

397

398

399

400

${ }^{11}$ Casey, K.S. and Adamec, D. Sea Surface Temperature and Sea Surface Height Variavility in the North Pacific Ocean from 1993 to 1999. Journal of Geophysical Research C: Oceans 107 (8), 14-1 (2002).

${ }^{12}$ Jones, M.S., Allen, M., Guymer, T., and Sounders, M. Correlations between Altimetric Sea Surface Height and Radiometric Sea Surface Temperature in the South Atlantic. Journal of Geophysical Rsearch Oceans 103, 8073-8087 (1998).

${ }^{13}$ Nezlin, N.P. and McWilliams, J.C. Satellite Data, Empirical Orthogonal Functions, and the 1997-1998 El Niño off California. Remote Sensing of Environment 84 (2), 234-254 (2003).

${ }^{14}$ Shi, J., Fedorov, A. V., \& Hu, S. A sea surface height perspective on El Niño diversity, ocean energetics, and energy damping rates. Geophysical Research Letters, 47(7), e2019GL086742 (2020).

${ }^{15}$ Harger, J.R.E. ENSO Variations and Drought Occurrence in Indonesia and the Philippines. Atmospheric Environment 29 (16), 1943-1955 (1995).

${ }^{16}$ Yumul, G.P., Dimalanta, C.B., Servando, N.T., and Hilario, F.D. El Niño Southern Oscillation in the Context of Climate Uncertainty: The Philippine Setting. Philippine Journal of Science 139 (1), 119-126 (2010).

${ }^{17}$ Ibarra, D. E., David, C. P. C., \& Tolentino, P. L. M. Evaluation and bias correction of an observation-based global runoff dataset using streamflow observations from small tropical catchments in the Philippines. Hydrology and Earth System Sciences, 25(5), 2805-2820 (2021).

${ }^{18}$ Rojas, O. Agricultural extreme drought assessment at global level using the FAO-Agricultural Stress Index System (ASIS). Weather and Climate Extremes, 27, 100184 (2020). 
${ }^{19}$ IPCC, 2021: Climate Change 2021: The Physical Science Basis. Contribution of Working Group I to the Sixth Assessment Report of the Intergovernmental Panel on Climate Change [Masson-Delmotte, V., P. Zhai, A. Pirani, S.L. Connors, C. Péan, S. Berger, N. Caud, Y. Chen, L. Goldfarb, M.I. Gomis, M. Huang, K. Leitzell, E. Lonnoy, J.B.R. Matthews, T.K. Maycock, T. Waterfield, O. Yelekçi, R. Yu, and B. Zhou (eds.)]. (Cambridge University Press, 2021)

${ }^{20}$ Taburet, G., Sanchez-Roman, A., Ballarotta, M., Pujol, M.I., Legeais, J.F., Fournier, F.,

${ }^{22}$ Bosch, W., Dettmering, D., and Schwatke, C. Multi-Mission Cross-Calibration of Satellite

414 Altimeters : Constructing a Long-Term Data Record for Global and Regional Sea Level

$415 \quad$ Change Studies. Remote Sensing 6 (3), 2255-2281 (2014).

$416{ }^{23}$ Watson, C.S., Legresy, B., and King, M.A. 'On the Uncertainty Associated with Validating the 417 Global Mean Sea Level Climate Record'. Advances in Space Research 68 (2), 487-495 $418 \quad$ (2021).

$419{ }^{24}$ Amiruddin, A.M., Haigh, I.D., Tsimplis, M.N., Calafat, F.M., and Dangendorf, S. The 420 Seasonal Cycle and Variability of Sea Level in the South China Sea. Journal of 421 Geophysical Research: Oceans 120 (8), 5490-5513 (2015).

$422{ }^{25}$ Andres, M., Musgrave, R.C., Rudnick, D.L., Zeiden, K.L., Peacock, T., and Park, J.H. On the 423 Predictability of Sea Surface Height around Palau. Journal of Physical Oceanography 50 
(11), 3267-3294 (2020).

\section{5}

426

427

428

429

430

431

432

433

434

435

436

437

438

439

${ }^{26}$ Lago, L.S., Saraceno, M., Ruiz-Etcheverry, L.A., Passaro, M., Oreiro, F.A., Donofrio, E.E., and Gonzalez, R.A. Improved Sea Surface Height from Satellite Altimetry in Coastal Zones: A Case Study in Southern Patagonia. IEEE Journal of Selected Topics in Applied Earth Observations and Remote Sensing 10 (8), 3493-3503 (2017).

${ }^{27}$ Luu, Q.H., Tkalich, P., and Tay, T.W. Sea Level Trend and Variability around Peninsular Malaysia. Ocean Science 11 (4), 617-628 (2015).

${ }^{28}$ Ghiggi, G., Humphrey, V., Seneviratne, S.I., and Gudmundsson, L. G-RUN ENSEMBLE : A Multi-Forcing Observation-Based Global Runoff Reanalysis. Water Resources Research 57 (5), 1-13 (2021).

${ }^{29}$ Ghiggi, G., Humphrey, V., Seneviratne, S.I., and Gudmundsson, L. GRUN: An ObservationsBased Global Gridded Runoff Dataset from 1902 to 2014. Earth System Science Data 11 (4), 1655-1674 (2019).

${ }^{30}$ Tolentino, P.L.M., Poortinga, A., Kanamaru, H., Keesstra, S., Maroulis, J., David, C.P.C., and Ritsema, C.J. Projected Impact of Climate Change on Hydrological Regimes in the Philippines. PLoS ONE 11 (10), e0163941 (2016). 
440 Extended Data Table 1. Correlation coefficients ( $r$-value) of $\log _{10}$-transformed river gauge data

441 with the corresponding $\log _{10}$-transformed GRUN and raw SSH data. The GRUN data analyzed are

442 within the grids where the river gauges are located. The time lag indicated in the correlation with

443 SSH refers to the time lag in months of SSH with the highest $r$-value. A positive time lag means

444 SSH precedes runoff; a negative time lag means SSH leads runoff.

\begin{tabular}{|c|c|c|c|c|}
\hline \multirow{2}{*}{ River } & \multirow{2}{*}{$\begin{array}{c}\text { Period covered of } \\
\text { analysis } \\
(\mathbf{m m} / \mathbf{y y y y})\end{array}$} & \multirow[b]{2}{*}{$\begin{array}{c}\text { Correlatio } \\
\text { nwith } \\
\text { GRUN } \\
\text { (r-value, p } \\
<0.05)\end{array}$} & \multicolumn{2}{|c|}{ Correlation with SSH } \\
\hline & & & $\begin{array}{l}\text { r-value } \\
(\mathrm{p}<0.05)\end{array}$ & $\begin{array}{c}\text { Time lag } \\
\text { (months, } \\
\text { with respect } \\
\text { to runoff) }\end{array}$ \\
\hline Agusan River & $01 / 1993-12 / 2009$ & 0.603 & 0.711 & -2 \\
\hline Cagayan River & $01 / 1993-12 / 2012$ & 0.859 & 0.747 & 0 \\
\hline Jalaur River & $01 / 1993-12 / 2010$ & 0.858 & 0.844 & -1 \\
\hline Libuganon River & $10 / 2000-12 / 2009$ & 0.627 & 0.389 & 0 \\
\hline $\begin{array}{c}\text { Cagayan de Oro } \\
\text { River }\end{array}$ & $01 / 1993-12 / 2004$ & 0.719 & 0.536 & 0 \\
\hline Sibuguey River & $01 / 1993-12 / 2010$ & 0.827 & 0.738 & 0 \\
\hline Sindangan River & $01 / 1993-12 / 2010$ & 0.785 & 0.831 & -1 \\
\hline
\end{tabular}

445 
446 Extended Data Table 2. Correlation coefficient values of national means, log GRUN vs. SSH and

447 SST at each time lag relative to SSH and SST. A positive time lag means SSH or SST precedes 448 runoff; a negative time lag means SSH or SST leads runoff.

\begin{tabular}{ccc}
\hline $\begin{array}{c}\text { Time lag } \\
\text { (months, SSH/SST } \\
\text { with respect to runoff })\end{array}$ & $\begin{array}{c}\log \text { GRUN vs SSH } \\
(1993-2019) \\
\text { r-value, } \mathrm{p}<0.05\end{array}$ & $\begin{array}{c}\log \text { GRUN vs SST } \\
(2002-2019) \\
\text { r-value, } \mathrm{p}<0.05\end{array}$ \\
\hline-8 & 0.570 & 0.689 \\
-7 & 0.638 & 0.721 \\
-6 & 0.699 & 0.734 \\
-5 & 0.752 & 0.729 \\
-4 & 0.793 & 0.707 \\
-3 & 0.821 & 0.667 \\
-2 & 0.835 & 0.612 \\
-1 & 0.833 & 0.543 \\
0 & 0.817 & 0.463 \\
1 & 0.787 & 0.375 \\
2 & 0.745 & 0.287 \\
3 & 0.693 & 0.203 \\
\hline
\end{tabular}

449 
450 Extended Data Table 3. Correlation coefficients (r-value) between the minimum GRUN during 451 each strong El Niño event and the SSH value at different time lags relative to the minimum GRUN.

452 Highlighted values are the maximum for each region across different time lags. The last row, 453 labeled "Min. SSH", corresponds to the r-value between the minimum GRUN and the minimum 454 SSH during each strong El Niño event, regardless of time lag.

\begin{tabular}{|c|c|c|c|c|c|c|c|c|c|}
\hline $\begin{array}{c}\text { Time } \\
\text { lag } \\
\text { (month } \\
\text { s) }\end{array}$ & $\begin{array}{c}\text { Palawa } \\
\mathrm{n}\end{array}$ & $\begin{array}{c}\text { Zambo } \\
\text { anga } \\
\text { and } \\
\text { Sulu }\end{array}$ & $\begin{array}{c}\text { W } \\
\text { Luzon }\end{array}$ & $\begin{array}{c}\text { Batane } \\
\text { s }\end{array}$ & $\begin{array}{c}\text { E } \\
\text { Luzon }\end{array}$ & $\begin{array}{c}\text { Cagaya } \\
n\end{array}$ & $\begin{array}{c}\text { E } \\
\text { Minda } \\
\text { nao } \\
\text { and } \\
\text { Samar }\end{array}$ & $\begin{array}{c}\text { Interna } \\
1 \text { Seas }\end{array}$ & $\begin{array}{c}\text { S } \\
\text { Minda } \\
\text { nao }\end{array}$ \\
\hline-6 & 0.560 & 0.762 & 0.508 & -0.062 & 0.321 & 0.246 & 0.509 & 0.638 & 0.728 \\
\hline-5 & 0.608 & 0.766 & 0.682 & 0.245 & 0.618 & 0.616 & 0.631 & 0.830 & 0.724 \\
\hline-4 & 0.782 & 0.683 & 0.841 & -0.035 & 0.663 & 0.772 & 0.700 & 0.835 & 0.706 \\
\hline-3 & 0.690 & 0.806 & 0.843 & 0.266 & 0.776 & 0.712 & 0.750 & 0.806 & 0.766 \\
\hline-2 & 0.814 & 0.846 & 0.909 & 0.711 & 0.783 & 0.630 & 0.807 & 0.840 & 0.754 \\
\hline-1 & 0.899 & 0.899 & 0.880 & 0.534 & 0.745 & 0.545 & 0.850 & 0.728 & 0.724 \\
\hline 0 & 0.924 & 0.931 & 0.912 & 0.558 & 0.694 & 0.492 & 0.878 & 0.623 & 0.781 \\
\hline $\begin{array}{l}\text { Min. } \\
\text { SSH }\end{array}$ & 0.878 & 0.914 & 0.937 & 0.574 & 0.828 & 0.832 & 0.824 & 0.862 & 0.901 \\
\hline
\end{tabular}




\section{Supplementary Files}

This is a list of supplementary files associated with this preprint. Click to download.

- SuppTable1.pdf 